\title{
A structural magnetic resonance imaging study in therapy-naïve transsexual individuals
}

\author{
A. Starcevic' ${ }^{1}$, M. Dakovic ${ }^{2}$, Z. Radojicic ${ }^{3}$, B. Filipovic ${ }^{1}$ \\ 1/nstitute of Anatomy, Medical Faculty, University of Belgrade, Serbia \\ ${ }^{2}$ Faculty for Physical Chemistry, University of Belgrade, Serbia \\ ${ }^{3}$ Faculty of Organisational Sciences, University of Belgrade, Serbia
}

[Received: 20 May 2020; Accepted: 1 July 2020]

Background: Transsexuality is explained and defined as a gender-identity disorder, characterised by very strong conviction of belonging to the opposite sex and has been associated with a distinct neuroanatomical pattern.

Materials and methods: We performed a structural analysis in search of possible differences in grey matter structures based on magnetic resonance imaging scans of the brains of 26 individuals between 19 and 38 years of age. The participants were divided into two groups of 15 controls and 11 transgender individuals. The segmentation of subcortical grey matter was performed using FIRST model a model-based segmentation/registration tool, from FSL software package.

Results: The results showed that the volume of the brain region called nucleus accumbens on the left side was significantly smaller in the group of transgender individuals compared to the control. It was the most important parameter which was shown to make distinction between two examined groups.

Conclusions: The results also showed decreased volumes of the left thalamus, right hippocampus and right caudate nucleus. (Folia Morphol 2021; 80, 2: 442-447)

Key words: transsexuals, magnetic resonance imaging, FSL, subcortical brain structures

\section{INTRODUCTION}

Transsexualism is defined as a gender identity inconsistency with their biologically assigned sex with a great desire for a sex reassignment therapy. It is no longer classified as a mental disorder in the International Statistical Classification of Diseases and Related Health Problems (ICD 11), but as a sexual health condition [11]. Exact and defined aetiology is still unknown, and sexual brain differentiation through embryonic development deviates from the sexual differentiation of the rest of the body. Neuroanatomy plays a crucial, highly important role in determining gender identity and therefore the investigation and defining the anatomical substrates and correlates can help us in identifying underlying mechanisms of transsexualism. Although public awareness is dramatically increased in past few decades, our scientific understanding and explanation of transsexualism is still very poor and pretty limited, as within every psychiatric condition where morphological substrate is not defined. It has been implicated that both environmental events and innate differences can influence and tribute to this condition. Sexual brain differentiation through embryonic development deviates from the sexual differentiation of the rest of the body [21]. This statement implicates to the fact that neuroanatomy

Address for correspondence: Dr. A. Starcevic, Institute of Anatomy, Medical Faculty, University of Belgrade, Dr Subotica 6, Belgrade, Serbia, e-mail: ana.starcevic22@gmail.com

This article is available in open access under Creative Common Attribution-Non-Commercial-No Derivatives 4.0 International (CC BY-NC-ND 4.0) license, allowing to download articles and share them with others as long as they credit the authors and the publisher, but without permission to change them in any way or use them commercially. 
plays a critical role in determining gender identity and therefore the investigation and defying the anatomical substrates and correlates can help us in identifying underlying mechanisms of transsexualism.

There were a number of studies that had examined brain structures in male to female (MtF) and female to male (FtM) transsexuals and some of them are postmortem studies. They gave a great tribute to the already claimed fact that brain anatomy is associated with transsexualism. Some of them did not show any significant result but two post mortem studies revealed a lot: MtF transsexuals had a female like central subdivision of the bed nucleus of the stria terminalis with respect to its size [21] and number of neurons [12]. Other post mortem study showed that MtF transsexuals had female like volumes and neuronal densities of the interstitial nucleus of the anterior hypothalamus [8]. All this findings were very crucial in defining in which direction further investigation will proceed because scientists are pretty limited by inherent pitfalls of postmortem studies and by small number of transsexual patients generally. In a voxel based morphometric study, a grey and white matter brain structures volumes were investigated in treatment naïve or hormone treated transgender women, and investigators concluded that differences existed in grey matter volumes in posterior superior frontal cortex in the cisgender women group [20]. Another magnetic resonance imaging (MRI) study showed regional grey matter structure differences in transsexuals compared to controls, independent from their biological gender in cerebellum, left angular gyrus, and in the left inferior parietal lobule [19].

In order of expanding the area of research, we investigated MRI neuroanatomy analysis and applied a very sophisticated computational image analysis approach to compare regional total volumes of different subcortical grey matter structures, caudate nucleus, putamen, globus pallidus, thalamus, hippocampus, amygdala, and nucleus accumbens.

\section{MATERIALS AND METHODS}

\section{Participants}

This research was conducted in accordance with the latest version of Declaration of Helsinki and approved by the local ethics committee and all included individuals provided written informed consent. All individuals arriving from the transgender outpatient service of the psychiatry department Clinical Centre
Dragisa Misovic in Belgrade, Serbia, diagnosed with gender identity disorder (GID) based on DSM-IV TR diagnostic criteria, were approached to enter a neuroimaging study. Both MtF and FtM individuals were eligible for the research. Healthy volunteers were recruited to serve as controls from among medical students, colleagues and friends of the research team who were free from any symptoms of GID or any psychiatric disorders. The presence of symptoms of GID was evaluated based on a free clinical interview asking simple questions targeting the symptoms of GID listed in DSM-IV TR, while the presence of psychiatric symptoms was assessed by SCL-90 [3]. Control subjects were selected to represent a population matched in age and gender identity to the patient group.

Only data from the structural imaging findings are presented in this paper, results of the functional imaging findings will be reported in upcoming publications.

\section{Diagnosis of GID}

All GID individuals underwent a detailed diagnostic interview with an expert psychiatrist in the field and also filled out a test battery assessing transgender identity disorder symptoms and associated behaviours and psychiatric comorbidity in order to confirm the diagnosis and exclude the presence of other mental disorder behind the symptoms of gender identity disorder. Sexual orientation of the patients was assessed by self-report. During the clinical interview basic demographic data, family history, psychiatric history and psychiatric status were also assessed.

\section{MRI acquisition}

Magnetic resonance examination of both transsexual and control subjects was performed using Siemens Avanto 1.5 T MRI device (Siemens, Erlangen., Germany) and 8-channel head coil. The imaging protocol consisted of T2 weighted spin echo (T2W, $\mathrm{TR}=4800 \mathrm{~ms}, \mathrm{TE}=94 \mathrm{~ms}$ ) and magnetisation prepared rapid acquisition gradient echo $\mathrm{T} 1$ weighted sequence (MPRAGE, TR $=1850 \mathrm{~ms}, \mathrm{TE}=5 \mathrm{~ms}$, flip angle $=12^{\circ}$, matrix: $512 \times 512$, isovoxel). T2W images were used to exclude presence of gross brain pathology in subjects. T1W images were transferred to PC workstation (Intel i5, 8GB ram, OS Ubuntu 14.04LTS) and converted to NifTI-1 (Neuroimaging Informatics Technology Initiative) using dcm2nii software. Orientation of images was checked/corrected using fslreorient2std script. 


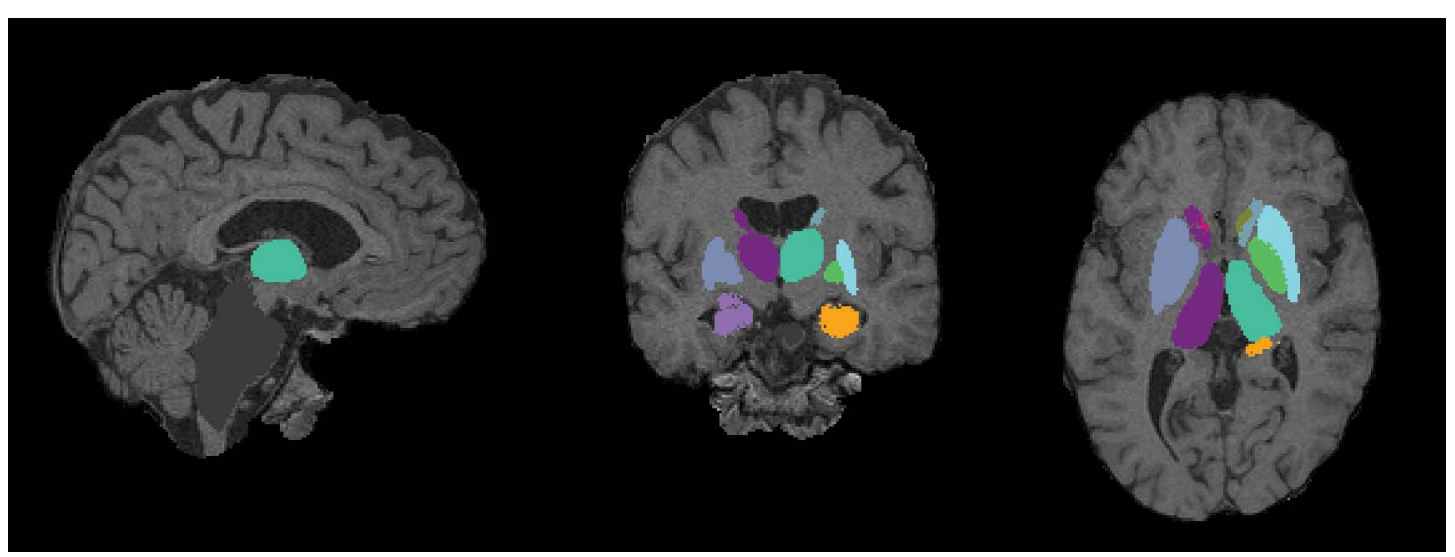

Figure 1. Example of segmentation of inner grey matter structures performed on single subject using FIRST (model based segmentation/registration tool, FSL software package).

The segmentation of subcortical grey matter was performed using the FIRST, the model based segmentation/registration tool, from FSL software package (Fig. 1) [17, 18]. The tool utilises the principles of the Active Shape and Appearance Models placed within a Bayesian framework. The models are trained for 15 different subcortical structures using 336 manually segmented and labelled T1-weighted MRI and statistical analysis was performed by R software [6].

\section{RESULTS}

We performed a structural analysis and searched for possible differences in grey matter structures based on MRI scans of the brains of 26 participants between 19 and 38 years of age, 15 controls and 11 transgender individuals. For statistical analysis, Kolmogorov-Smirnov test was used to test normal distribution of examined parameters. All parameters had a normal distribution ( $p>0.05)$. To test average values of the parameters Student t-test and Levene's test for equality of variances were done. Binomial logistic regression was used to apostrophe important parameters for group prediction. Receiver operating characteristic (ROC) analysis was done for important parameters to emphasise sensitivity and specificity of each parameter and to remark cut-off values (points). All analyses were done on a level of significate $p<0.05$. Analyses were done in SPSS 24 software package. The results showed that the volume of the brain region called nucleus accumbens on the left side was significantly smaller in the group of transgender people compared to the control. It was the
Table 1. Comparison of the groups for each examined subcortical structure

\begin{tabular}{|c|c|c|c|c|c|c|}
\hline $\begin{array}{l}\text { Group } \\
\text { statistics }\end{array}$ & Group & $\mathbf{N}$ & Mean & $\begin{array}{l}\text { Standard } \\
\text { deviation }\end{array}$ & $\begin{array}{c}\text { Standard } \\
\text { error } \\
\text { mean }\end{array}$ & $\mathbf{P}$ \\
\hline Age & $\begin{array}{l}\text { Trans } \\
\text { Control }\end{array}$ & $\begin{array}{l}11 \\
15\end{array}$ & $\begin{array}{l}26.91 \\
29.07\end{array}$ & $\begin{array}{l}7.503 \\
8.259\end{array}$ & $\begin{array}{l}2.262 \\
2.132\end{array}$ & 0.501 \\
\hline $\begin{array}{l}\text { Thalamus } \\
\text { Vol L }\end{array}$ & $\begin{array}{l}\text { Trans } \\
\text { Control }\end{array}$ & $\begin{array}{l}11 \\
15\end{array}$ & $\begin{array}{l}8212.13 \\
7673.41\end{array}$ & & $\begin{array}{l}188.12 \\
216.46\end{array}$ & 0.085 \\
\hline $\begin{array}{l}\text { Thalamus } \\
\text { Vol R }\end{array}$ & $\begin{array}{l}\text { Trans } \\
\text { Control }\end{array}$ & $\begin{array}{l}11 \\
15\end{array}$ & & & & \\
\hline $\begin{array}{l}\text { Caudatus } \\
\text { Vol L }\end{array}$ & $\begin{array}{l}\text { Trans } \\
\text { Control }\end{array}$ & $\begin{array}{l}11 \\
15\end{array}$ & & & $\begin{array}{l}164.27 \\
78.11\end{array}$ & 0.020 \\
\hline $\begin{array}{l}\text { Caudatus } \\
\text { Vol R }\end{array}$ & & $\begin{array}{l}11 \\
15\end{array}$ & & & & 0.185 \\
\hline $\begin{array}{l}\text { Putamen } \\
\text { Vol L }\end{array}$ & & $\begin{array}{l}11 \\
15\end{array}$ & & & & 0.525 \\
\hline $\begin{array}{l}\text { Putamen } \\
\text { Vol R }\end{array}$ & $\begin{array}{l}\text { Trans } \\
\text { Control }\end{array}$ & $\begin{array}{l}11 \\
15\end{array}$ & & & & 0.005 \\
\hline $\begin{array}{l}\text { Pallidum } \\
\text { Vol L }\end{array}$ & & $\begin{array}{l}11 \\
15\end{array}$ & & & $\begin{array}{l}58.14 \\
67.04\end{array}$ & 0.571 \\
\hline $\begin{array}{l}\text { Pallidum } \\
\text { Vol R }\end{array}$ & $\begin{array}{l}\text { Trans } \\
\text { Control }\end{array}$ & $\begin{array}{l}11 \\
15\end{array}$ & $\begin{array}{l}1817.34 \\
1783.14\end{array}$ & $\begin{array}{l}185.10 \\
306.78\end{array}$ & $\begin{array}{l}55.81 \\
79.21\end{array}$ & 0.746 \\
\hline $\begin{array}{l}\text { Hippocam- } \\
\text { pus Vol L }\end{array}$ & $\begin{array}{l}\text { Trans } \\
\text { Control }\end{array}$ & $\begin{array}{l}11 \\
15\end{array}$ & $\begin{array}{l}3562.27 \\
3825.74\end{array}$ & & $\begin{array}{l}139.25 \\
115.00\end{array}$ & 0.155 \\
\hline $\begin{array}{l}\text { Hippocam- } \\
\text { pus Vol R }\end{array}$ & $\begin{array}{l}\text { Trans } \\
\text { Control }\end{array}$ & $\begin{array}{l}11 \\
15\end{array}$ & $\begin{array}{l}3611.82 \\
3973.05\end{array}$ & $\begin{array}{l}342.21 \\
313.83\end{array}$ & $\begin{array}{l}103.18 \\
81.03\end{array}$ & 0.010 \\
\hline $\begin{array}{l}\text { Amygdala } \\
\text { Vol L }\end{array}$ & $\begin{array}{l}\text { Trans } \\
\text { Control }\end{array}$ & $\begin{array}{l}11 \\
15\end{array}$ & $\begin{array}{l}1248.97 \\
1185.74\end{array}$ & $\begin{array}{l}225.57 \\
198.32\end{array}$ & $\begin{array}{l}68.01 \\
51.20\end{array}$ & 0.456 \\
\hline $\begin{array}{l}\text { Amygdala } \\
\text { Vol R }\end{array}$ & $\begin{array}{l}\text { Trans } \\
\text { Control }\end{array}$ & $\begin{array}{l}11 \\
15\end{array}$ & $\begin{array}{l}1338.66 \\
1239.34\end{array}$ & $\begin{array}{l}402.57 \\
249.81\end{array}$ & $\begin{array}{c}121.38 \\
64.50\end{array}$ & 0.445 \\
\hline $\begin{array}{l}\text { Accum- } \\
\text { bens Vol L }\end{array}$ & $\begin{array}{l}\text { Trans } \\
\text { Control }\end{array}$ & $\begin{array}{l}11 \\
15\end{array}$ & $\begin{array}{l}514.07 \\
605.47\end{array}$ & $\begin{array}{c}68.60 \\
105.74\end{array}$ & $\begin{array}{l}20.68 \\
27.30\end{array}$ & 0.020 \\
\hline $\begin{array}{l}\text { Accum- } \\
\text { bens Vol R }\end{array}$ & $\begin{array}{l}\text { Trans } \\
\text { Control }\end{array}$ & $\begin{array}{l}11 \\
15\end{array}$ & $\begin{array}{l}382.42 \\
439.62\end{array}$ & $\begin{array}{l}70.86 \\
77.46\end{array}$ & $\begin{array}{l}21.37 \\
20.00\end{array}$ & 0.066 \\
\hline
\end{tabular}


most important parameter which was shown to make distinction between two examined groups. The results also showed decreased volumes of the left thalamus, right hippocampus and right caudate nucleus.

The Student's T test was used for the group comparison, and the results are shown in Table 1.

The groups were equal to the age structure $(p=0.501)$. Differences in the values in the values of thalamus Vol $R(p=0.025)$ and caudatus Vol $R(p=0.020)$ where the values "Trans" groups were statistically significantly higher. With the viewed parameters of putamen Vol R ( $p=0.005)$, hippocampus Vol $R$

Table 2. Binomial multivariate logistics regression analysis, method stepwise forward conditional

\begin{tabular}{lccc}
\hline & B & Standard error & Hazard ratio \\
\hline Thalamus Vol L & -0.097 & 13.623 & 0.908 \\
Caudatus Vol R & 0.067 & 13.337 & 1.070 \\
Hippocampus Vol R & 0.054 & 24.948 & 1.055 \\
Accumbens Vol L & 0.387 & 60.312 & 1.473 \\
\hline
\end{tabular}

$(p=0.010)$ and accumbens Vol $L(p=0.020)$ the values of "Trans" groups were statistically significantly reduced.

In order to discover the parameters of importance that diversify the observed groups, binomial multivariate logistics regression was used, method stepwise, from the point of view of joint action. At the start, the overall prediction was $57.5 \%$, after four steps using forward conditional method, overall prediction showed $100 \%$. The results of binomial logistics regression are shown in Table 2 .

To confirm binomial multivariate logistic regression, for each important variable ROC analysis were done. The results confirmed the obtained logistic regression solution. In order to find breakdown values that will indicate the observed Trans group was done (Table 3 ), and a method $\mathrm{P} / \mathrm{N}$ ratio was used to determine the cut off points. The table shows significance, value cut off and the degree of sensitivity and specificity for the given value presenting left nucleus accumbens as most important parameter (area under the curve $[\mathrm{AUC}]=0.824)($ Figs. 2, 3).

Table 3. Results of area under the curve (AUC) and cut-off point with sensitivity and specificity were calculated for each given parameter

\begin{tabular}{lcccccccc}
\hline Parameter & AUC & $\mathbf{P}$ & $\mathbf{9 5 \%}$ CI L & $\mathbf{9 5 \% ~ C I ~ U ~}$ & Cut-off & Sensitivity & Specificity & Values* $^{*}$ \\
\hline Thalamus Vol L & 0.76 & $\mathbf{0 . 0 2 4}$ & 0.57 & 0.95 & 7729 & 0.818 & 0.733 & Bigger \\
Caudatus Vol R & 0.74 & $\mathbf{0 . 0 4 0}$ & 0.53 & 0.95 & 3533 & 0.636 & 0.667 & Bigger \\
Hippocampus Vol R & 0.79 & $\mathbf{0 . 0 1 2}$ & 0.61 & 0.98 & 3798 & 0.818 & 0.800 & Smaller \\
Accumbens Vol L & 0.82 & $\mathbf{0 . 0 0 5}$ & 0.66 & 0.99 & 561 & 0.818 & 0.733 & Smaller \\
\hline
\end{tabular}

${ }^{*}$ To the "Trans" group compared to cut off point; $\mathrm{Cl}$ — confidence interval; $\mathrm{L}$ — lower; $\mathrm{U}$ - upper

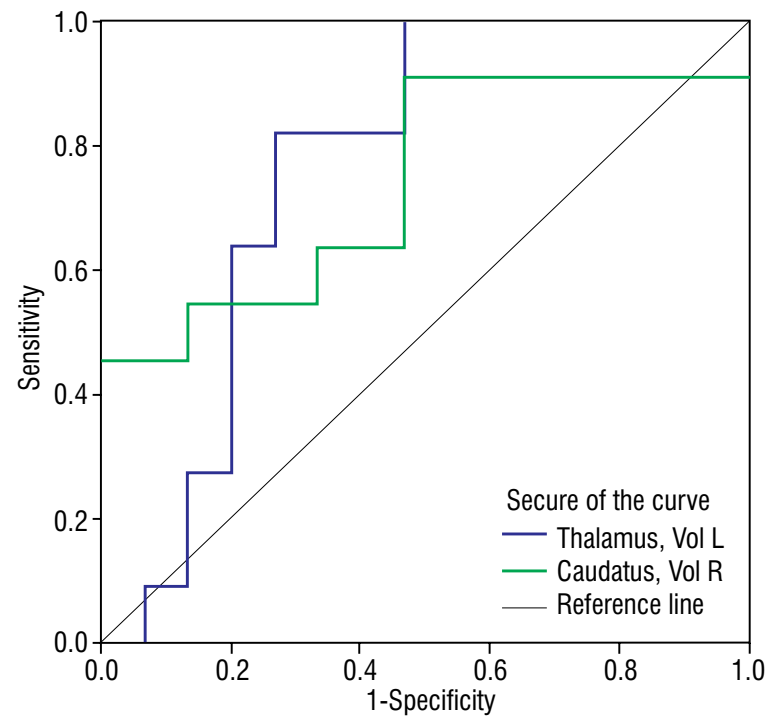

Figure 2. Receiver operating characteristic curve for left thalamus and right caudatus.

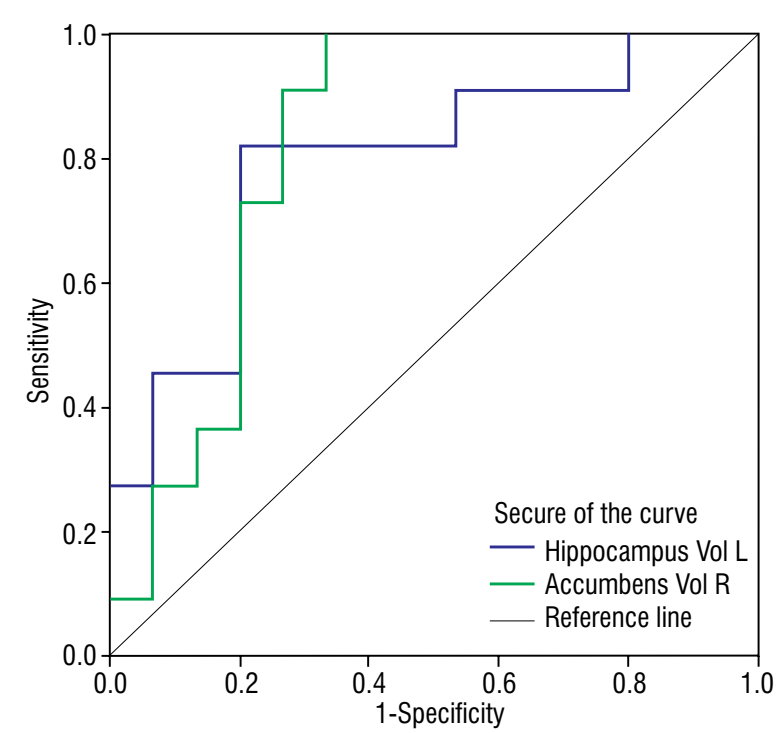

Figure 3. Receiver operating characteristic curve for left accumbens and right hippocampus. 


\section{DISCUSSION}

Nucleus accumbens is, anatomically spoken, round and dorsally flattened structure located anteriorly to the anterior commissure, its posterior part, and dorsomedially into the caudate nucleus [10]. Strict delineation between these two structures is previously thought to be almost impossible, especially with MRI, but more recent studies have suggested that discerning the nucleus accumbens limits with the caudate nucleus is easier by T2-weighted MRIs due to the more intense signalling showing of nucleus accumbens than the caudate nucleus. Our study showed decreased left nucleus accumbens volume which is correlated with previous explanation [13,15].

Many morphometric studies showed increased volume of nucleus accumbens on the left and right in males with or without gender or cerebral differences $[1,4,13-15]$. Another parameter that was included as very important was age, which was mentioned as a very important parameter when referring a decrease in specific brain structure volume correlated with age, while other structures do not pinpoint to age-related volume decrease $[4,13,14]$. Our results showed decreased volume on the left side predominantly in FtM subjects and in one MtF, and they were in their ages of 21 years, 23 years, and 39 years, which we cannot consider as age related atrophy.

The results showed that the volume of the left nucleus accumbens was smaller in transgender group consisted of both FtM and MtF than in healthy ones. Beside nucleus accumbens, we found decreased volumes of left thalamus and right hippocampus and caudate nucleus, but statistically it was shown that left nucleus accumbens was the most significant parameter. Nucleus accumbens is very important structure of ventral striatum and one of the major subcortical structures involved in emotional processes, anxiety disorders, bipolar disorder, many other neurological and psychiatric disorders as well as in addictions. It was known to be one of the key structures in addiction and drug reward circle. It would be easy to directly connect to the transgender individuals, but we can say that verification of a different volume or simply a difference in left nucleus accumbens is relevant since transgender individuals have many problems related to be accepted from their family and society, they have that strong feeling of being trapped into their own body and consequently their perception is different. Due to the fact mentioned previously, transgender people go through discrimination and persecution and often suffer from different anxiety problems, depression, addiction issues, bipolar disorder and many others.

It is worth mentioning that an important diagnostic criterion for gender dysphoria is the distress that accompanies the incongruity between the body and gender identity, as the secondary sexual characteristics do not belong to the gender with which one identifies [7].

As for the decreased volumes of right thalamic and caudate structures, Nota et al. [16] showed that within the right working memory network, cisgender males showed significantly greater functional connectivity in the right caudate nucleus than cisgender females.

Moreover, later research has shown very similar delay of active neurons also in the posterior parietal cortex, the thalamus, the caudate, and the globus pallidus [2].

In addition to the reported regional volumetric characteristics, it is very significant to take into account human brain network connectome and morphological substrates included, which enables an investigation of interactions across brain regions and hence have provided valuable insights in fundamental human brain function. In a study investigating structural connectome of FtM and MtF, transsexuals before hormonal treatment showed differences specifically for connections between subcortical, limbic and cortical regions [5, 9]. Subcortical brain segmentation and volumetry findings put on complementary information as the evaluation on a network level between subcortical structures and cortex revealed specific characteristics for transsexuals [9].

\section{CONCLUSIONS}

Our findings support the theory that structural differences exist between transsexual individuals and controls from the same biological gender. We found that that the volume of the brain region called nucleus accumbens on the left side was significantly smaller in the group of transgender patients compared to the control. It was the most important parameter which was shown to make distinction between two examined groups. The results also showed decreased volumes of the left thalamus, right hippocampus and right caudate nucleus.

Disadvantage of this investigation is the fact of sample sizes which is modest and results are therefore yet inconclusive in details, but still significant struc- 
tural differences were found between transsexuals and controls. These initial results, the results of our study, need to be further replicated and refined in future studies on larger samples, as well as followed by functional imaging studies that might clarify how these structural differences impact the process of the evolution of gender identity and its affection on specific brain structures as well as their emotional regulation, cognitive ability and brain lateralisation.

\section{REFERENCES}

1. Ahsan RL, Allom R, Gousias IS, et al. Volumes, spatial extents and a probabilistic atlas of the human basal ganglia and thalamus. Neuroimage. 2007; 38(2): 261-270, doi: 10.1016/j.neuroimage.2007.06.004, indexed in Pubmed: 17851093.

2. Ashby FG, Ell SW, Valentin VV, et al. FROST: a distributed neurocomputational model of working memory maintenance. J Cogn Neurosci. 2005; 17(11): 1728-1743, doi: 10.1162/089892905774589271, indexed in Pubmed: 16269109.

3. Blanchard J, Brown S. Structured diagnostic interview schedules. Comprehensive Clinical Psychology. 1998; 4: 97-130, doi: 10.1016/b0080-4270(73)00003-1.

4. Brabec J, Krásený J, Petrovický P. Volumetry of striatum and pallidum in man - anatomy, cytoarchitecture, connections, MRI and aging. Sb Lek. 2003; 104(1): 13-65, indexed in Pubmed: 14577136.

5. Cohen-Kettenis PT, van Goozen SH, Doorn CD, et al. Cognitive ability and cerebral lateralisation in transsexuals. Psychoneuroendocrinology. 1998; 23(6): 631-641, doi: 10.1016/ s0306-4530(98)00033-x, indexed in Pubmed: 9802133.

6. Development Core Team. R. A language and environment for statistical computing [Internet]. 2016; Vienna: R Foundation for Statistical Computing. http://www.r-project. org/.

7. Fisher AD, Castellini G, Bandini E, et al. Cross-sex hormonal treatment and body uneasiness in individuals with gender dysphoria. J Sex Med. 2014; 11(3): 709-719, doi: 10.1111/ jsm.12413, indexed in Pubmed: 24330520.

8. Garcia-Falgueras A, Swaab DF. A sex difference in the hypothalamic uncinate nucleus: relationship to gender identity. Brain. 2008; 131(Pt 12): 3132-3146, doi: 10.1093/ brain/awn276, indexed in Pubmed: 18980961.

9. Hahn A, Kranz GS, Küblböck M, et al. Structural Connectivity Networks of Transgender People. Cereb Cortex. 2015; 25(10): 3527-3534, doi: 10.1093/cercor/bhu194, indexed in Pubmed: 25217469.

10. Johnston JB. The morphology of the septum, hippocampus, and pallial commissures in repliles and mammals.
J Comp Neurol. 1913; 23(5): 371-478, doi: 10.1002/ cne.900230502.

11. Kacala A. Being Trans Is (Finally) No Longer Classified as a Mental Disorder by the WHO. 2018; Hornet.

12. Kruijver FP, Zhou JN, Pool CW, et al. Male-to-female transsexuals have female neuron numbers in a limbic nucleus. J Clin Endocrinol Metab. 2000; 85(5): 2034-2041, doi: 10.1210/jcem.85.5.6564, indexed in Pubmed: 10843193.

13. Mavridis I, Boviatsis E, Anagnostopoulou S. Anatomy of the human nucleus accumbens: a combined morphometric study. Surg Radiol Anat. 2011; 33(5): 405-414, doi: 10.1007/s00276-010-0766-6, indexed in Pubmed: 21203764.

14. Mavridis I, Boviatsis E, Anagnostopoulou S. Stereotactic anatomy of the human nucleus accumbens: from applied mathematics to microsurgical accuracy. Surg Radiol Anat. 2011; 33(7): 583-594, doi: 10.1007/s00276-011-0804-z, indexed in Pubmed: 21437651.

15. Neto LL, Oliveira E, Correia F, et al. The human nucleus accumbens: where is it? A stereotactic, anatomical and magnetic resonance imaging study. Neuromodulation. 2008; 11(1): 13-22, doi: 10.1111/j.1525-1403.2007.00138.x, indexed in Pubmed: 22150987.

16. Nota NM, Burke SM, den Heijer M, et al. Brain sexual differentiation and effects of cross-sex hormone therapy in transpeople: A resting-state functional magnetic resonance study. Neurophysiol Clin. 2017; 47(5-6): 361-370, doi: 10.1016/j.neucli.2017.09.001, indexed in Pubmed: 29029883.

17. Patenaude B, Smith SM, Kennedy DN, et al. A Bayesian model of shape and appearance for subcortical brain segmentation. Neuroimage. 2011; 56(3): 907-922, doi: 10.1016/j.neuroimage.2011.02.046, indexed in Pubmed: 21352927.

18. Patenaude BM. Bayesian statistical models of shape and appearance for subcortical brain segmentation [Internet] [Ph.D.]. 2007; University of Oxford. http://ora.ox.ac.uk/ objects/uuid:52f5fee0-60e8-4387-9560-728843e187b3.

19. Simon L, Kozák LR, Simon V, et al. Regional grey matter structure differences between transsexuals and healthy controls - a voxel based morphometry study. PLoS One. 2013; 8(12): e83947, doi: 10.1371/journal.pone.0083947, indexed in Pubmed: 24391851.

20. Spizzirri G, Duran FL, Chaim-Avancini TM, et al. Grey and white matter volumes either in treatment-naïve or hormone-treated transgender women: a voxel-based morphometry study. Sci Rep. 2018; 8(1): 736, doi: 10.1038/ s41598-017-17563-z, indexed in Pubmed: 29335438.

21. Zhou JN, Hofman MA, Gooren $\amalg$, et al. A sex difference in the human brain and its relation to transsexuality. Nature. 1995; 378(6552): 68-70, doi: 10.1038/378068a0, indexed in Pubmed: 7477289. 